\title{
Çoklu Ortam Tasarımı Destekli Yapılandırmacı Öğretim Etkinliklerinin Öğrencilerin Akademik Başarılarına Etkisi ${ }^{1}$
}

\author{
DOI: $10.26466 / o p u s .774891$
}

*

\author{
Cemal Akyol * -Sabahattin Çiftçi** \\ * Arş. Gör. Dr., Selçuk Üniversitesi, Konya \\ E-Posta: cemal akyol@yahoo.com \\ ORCID: $\underline{0000-0001-9125-3529}$ \\ **Prof. Dr., Necmettin Erbakan Üniversitesi, Konya \\ Öz \\ ORCID: $\underline{0000-0002-5437-9867}$
}

Bu araştırmanın genel amacı çoklu ortam tasarımı destekli yapılandırmacı öğretim etkinliklerinin ortaokulda okuyan öğrenciler üzerindeki etkisini araştırmaktır. Bu amaç doğrultusunda ortaokul 7. Sinıf Fen Bilimleri dersi kapsamında gerçekleştirilen çoklu ortam tasarımı destekli yapılandırmacı öğretim etkinliklerinin, öğrencilerin akademik başarılarına etkisi araştırılmıştır. Deneysel uygulamanın öğrenme ürünleri üzerindeki etkilerini saptamak için nicel araştırma yöntemlerinden "ön-test/son-test kontrol gruplu deneysel desen" kullanılmıştır. Araştırmanın çalışma grubunu, Konya il merkezinde eğitim veren bir ortaokulun 7. sinıfinda öğrenim gören 66 öğrenci oluşturmaktadır. Araştırma 7. sınıf Fen Bilimleri dersi kapsamında gerçekleştirilmiştir. Araştırmada rastgele seçilen bir deney ve bir kontrol grubu olmak üzere iki grup bulunmaktadır. Kontrol grubunda mevcut programa göre fen bilimleri dersi yapılmıştır. Deney grubunda ise mevcut programa ek olarak araştırmacı tarafindan tasarlanan çoklu ortam tasarımı destekli yapılandırmacı öğretim etkinlikleri uygulanmıştır. Araştırmanın verilerinin analizinde betimsel istatistikler, bağımsız örneklem $t$-testi ve tek yönlü kovaryans analizi (ANCOVA) kullanılmıştır.

Araştırmanın sonuçlarına göre çoklu ortam tasarımı destekli yapılandırmacı öğretim etkinliklerinin ö̆grencilerin akademik başarıların olumlu yönde etkilediği ortaya çıkmıştırtimsel istatistikler, bağımsız örneklem t-testi ve tek yönlü kovaryans analizi (ANCOVA) kullanılmıştır.

Anahtar Kelimeler: Çoklu ortam tasarımı, Multimedya, Yapılandırmacılık, Scratch, Akademik başarı.

${ }^{1}$ ilk yazarın doktora tezinden üretilmiştir. 


\title{
The Impact Of Academic Achievement Of Constructivist Teaching Activities With Multimedia Design On Students
}

\begin{abstract}
The general aim of this research was to investigate the effects of multimedia aided constructivist teaching activities on secondary school students. Accordingly, the effects of multimedia aided constructivist teaching activities implemented in 7 th grade Science Course were examined in terms of students' academic achievement.

A pre-test post-test control group design, one of the quantitative research methods, was used in order to determine the effects of the experimental application on learning products. The study group consisted of 66 students attending the 7th grade of a secondary school in Konya city centre. The research was conducted in 7 th grade Science Course. In the study, there were randomly selected two groups, one experimental and one control group. The course was given according to the current Science curriculum in the control group. On the other hand, multimedia aided constructivist teaching activities, which were designed by the researcher, were implemented in the experimental group in addition to the current Science curriculum. Descriptive statistics, independent samples $t$-test and one-way covariance analysis (ANCOVA) were used to analyze the quantitative data of the study.

The findings of the research concluded that multimedia aided constructivist teaching activities had a positive effect on students' academic achievement.
\end{abstract}

Keywords: Multimedia course design, Multimedia, Constructivism, Scratch, Academic achievement. 


\section{Giriş}

Bilgi çağının yaşandığı dünyada bilgiye ulaşma, bilgiyi kullanma ve üretme gibi beceriler toplumların geleceğini şekillendiren önemli faktörlerdir. Bireylerin bu becerileri kazanması için çağdaş eğitim programlarına ve yenilikçi öğrenme yaklaşımlarına ihtiyaç vardır. Geleneksel yaklaşımların yetersiz kaldığı dönemde bilginin temelden kurulmasına dayanan ve öğrenenlerin bilgiyi nasıl yapılandırdıklarına ilişkin bir yaklaşım olan yapılandırmacılık yaklaşımı ön plana çıkmıştır. Yapılandırmacılık, öğrenenlerin bilgiyi nasıl öğrendikleriyle ilgilenen bir kuram olarak ortaya çıkmış ve zamanla öğrenenlerin bilgiyi nasıl yapılandırdıklarına ilişkin bir yaklaşım haline gelmiştir. Bireyin bilgiyi yapılandırmasında kendi yaşantıları önem taşımaktadır. Bireyler karşlaştıkları yeni durumlara, bilgiye, kavramlara kendisinde var olan anlamlara ve zihinsel yapılara göre anlam verir. Mevcut anlamlar ve zihinsel yap1lar karşılaştığı yeni bilgi, yeni durum için uygunluk sağlamadığı takdirde ya var olan yapıda değişiklik yapılır ya da tamamen yeni bir yapı oluşturulur. Yapılandırmacı anlayışta öğrenme aktif bir süreçtir. Bu süreçler öğrenenler bilgilerini gerçek yaşam durumlarında daha önce öğrendikleri deneyimleri/bilgileri ile ilişkilendirirler (Brooks ve Brooks, 1993; Demirel, 2012; Jonassen, 1994; Hesapçıŏlu, 2011; Perkins, 1999; Senemoğlu, 2009). Yapılandırmacllıkta öğrenme ezberlemeye değil, öğrenenin bilgiyi transfer etmesine, bilgiyi yorumlamasına ve yeni bilgi oluşturmasına dayanır. Önceden öğrenilmiş bilgi ile yeni öğrenilen bilgi uyumlu hale getirilerek yapılandırılan bilgi, yaşamda karşılaşılan problemleri çözmede kullanılabilecektir (Perkins, 1999). Yapılandırmacılık yaklaşımında öğrenciler, öğretme öğrenme sürecinde etkin olmalıdır. Bu sebepten dolayı yapılandırmacı sınıf ortamları geleneksel yöntemlerle sadece bilginin aktarıldığı değil, öğrencinin derse etkin katıl1mını sağlayan, sorgulama, araştırma yapma ve problem çözmeye uygun ortamlar olarak oluşturulmalıdır. Sınıf içi etkinlikler ise öğrencilerin zengin öğrenme yaşantıları geçirebilecek şekilde yapılandırılmalıdır. Yapılandırmacılık yaklaşımında gerekli olan bu sınıf ortamları ve etkinlikler mevcut öğretim programları çerçevesinde öğretmenler tarafından uygulanmaktadır. Ancak uygulamalarda birtakım sorunlar ortaya çıkmaktadır. Yapılan araştırmalar yapılandırmacılık yaklaşımına uygun öğrenme ortamları ve etkinlikleri ko- 
nusunda öğretmenlerin tutumlarının yüksek olduğu ancak uygulama konusunda bilgi ihtiyacı ve teknoloji konusunda fiziki ihtiyaçların olduğunu ortaya çıkarmaktadır (Arslan, 2008; Eskici, 2013; Kurtdede Fidan, 2010).

Teknolojinin hızla gelişmesi hayatın her alanında etkilerini göstermektedir. Özellikle eğitim alanında birçok yeniliğin gerçekleştirilmesine olanak sağlamaktadır. Türkiye'de eğitim alanında teknolojik yatırımlar son dönemlerde ağırlık kazanmıştır. FATïH projesi ile tüm sınıfların akıllı tahta, internet bağlantısı, projeksiyon cihazı gibi teknolojik imkanlarla donatılması ve ayrıca tüm öğrencilere ve öğretmenlere de ücretsiz tablet bilgisayarlar dağıtılması planlanarak eğitimde teknolojiden en üst düzeyde yararlanılması amaçlanmıştır. Öğrenenlerin yapılandırmacılık anlayışına uygun zengin öğrenme yaşantıları geçirebilmesi için gerekli ortamlarının tasarlanmasında teknolojiden yararlanılması gerekmektedir (Jonassen, 1999). Eğitim alanında teknolojik imkanlardan en çok yararlanılan bilgisayarlar aracılığıyla öğrenciler, hikayeler, interaktif oyunlar, animasyonlar, simülasyonlar gibi çeşitli çoklu ortam araçlarına ulaşabilir ve bunları eğitsel amaçlar için kullanabilirler. Ancak başkalarının yaptığı sınırlı sayıda olan bu yazılımları yalnızca kullanabilir ama kendileri yapamazlar. Bilgisayarda yazılım geliştirmek, oyunlar veya animasyonlar hazırlamak zor ve uzmanlık gerektiren bir iş olarak görülür (Jenkins, 2002). Tüm bu olumsuz şartları ortadan kaldırabilmek için MIT tarafından Scratch adında bir yazılım hazırlanmış ve ücretsiz olarak herkesin kullanımına sunulmuştur. Scratch yazılımı iki boyutlu zengin çoklu ortam araçları oluşturulmasına imkan sağlayan görsel bir programlama aracıdır. Bu yazılım yardımıyla çok çeşitli oyunlar, animasyonlu hikayeler, tebrik kartları, müzik videoları, bilim projeleri, eğitimler, simülasyonlar ve sanat projeleri gibi ortamlar kolay bir şekilde oluşturulabilmektedir. Scratch yazılımında kodlama sistemi renkli ve birbirlerini tamamlayacak şekilde bloklar olarak tasarlanmıştır. Bu tasarım kodlama yapmayı hem görsel hem de kolay hale getirmiştir. Scratch yazılımı özellikle 8-16 yaş grubu çocuklar için tasarlanmış olmakla birlikte her yaştan insan tarafından kullanılmaktadır. Yazılım, Türkçe de dahil 50 faklı dil seçeneğiyle kullanıma sunulduğu 2007 yılından itibaren iki milyondan fazla kişi tarafından indirilmiştir. Sonuç olarak Scratch yazılımı öğrenilmesi kolay, karmaşık projelerin kolayca yapılabildiği ve proje çeşitliliğinin desteklendiği bir ortam halini almıştır (Maloney vd., 2010; Genç ve Karakuş, 2011). Eğitim-öğretim sürecinde bilişim teknolojisi donanımlarını kul- 
lanarak etkin materyallerin kullanılması amacıyla Yenilik ve Eğitim Teknolojileri Genel Müdürlüğü tarafından tasarlanan Eğitim Bilişim Ağı (EBA) kapsamında Türkçe olarak eğitim videolarının hazırlanmasıyla Scratch yazılımının kullanımı Milli Eğitim Bakanlığı tarafından teşvik edilmiştir. İlgili literatür incelendiğinde ise öğrencilerin var olan çoklu ortamları kullanmaktan çok Scratch türünde yazılımlar yardımıyla kendi ürettikleri projelerle motivasyonlarının yükseldiği ve daha fazla araştırma yapma isteği duydukları yapılan araştırmalarda ortaya konmuştur (Maloney vd., 2008; Resnick vd., 2009; Peppler ve Kafai, 2007).

Teknolojik gelişmeler eğitim alanında etkisini göstermekte ve mevcut öğretim etkinliklerinin zenginleştirilmesine olanak sağlamaktadır. Yapılandırmacılık yaklaşımının merkezde olduğu mevcut eğitim programları göz önüne alındığında, öğretim etkinliklerinin daha zengin hale getirilmesi öğrencilerin motivasyonunu, ilgisini ve dikkatini artıracak ve öğrenmenin daha etkili, eğlenceli ve kalıcı olması sağlanabilecektir. Bu bağlamda teknoloji vasitasıyla oluşturulan çoklu ortamların kullanımı eğitimde bir fark oluşturmaktadır. Ancak eğitimde kullanılan çoklu ortamlar genellikle öğretmenler veya uzmanlar tarafından tasarlanıp oluşturulmaktadır. Bu durumda öğrencinin pasif, öğretmenin aktif olması yapılandırmacı yaklaşımın ilkelerine ters düşmektedir. Bu bağlamda yapılandırmacı yaklaşıma uygun olarak öğrencilerin kendi çoklu ortam materyallerini oluşturdukları ve aktif olarak eğitim sürecine dahil oldukları bu araştırmanın genel amacı çoklu ortam tasarımı destekli yapılandırmacı öğretim etkinliklerinin ortaokulda okuyan öğrenciler üzerindeki etkisini araştırmak olmuştur. Bu amaç doğrultusunda ortaokul 7. Sınıf Fen Bilimleri dersi kapsamında gerçekleştirilen çoklu ortam tasarımı destekli yapılandırmacı öğretim etkinliklerinin, öğrencilerin akademik başarılarına etkisi araştırılmıştır.

\section{Yöntem}

Araştırmada deneysel uygulamanın öğrencilerin akademik başarıları üzerindeki etkilerinin belirlenebilmesi için nicel araştırma yöntemlerinden ön-test son-test kontrol gruplu yarı deneysel desen kullanılmıştır. Deney ve kontrol grubunun seçiminde rasgele atama yapılmamış ve araştırmanın bağımlı değişkeni olan akademik başarı bakımından grupların denk gruplar olmasına dikkat edilmiştir. 


\section{Çalışma Grubu}

Bu araştırmanın çalışma grubunu Konya il merkezindeki bir devlet ortaokulunun 7. sınıfında öğrenim gören 66 öğrenci oluşturmaktadır. Bu öğrencilerden 33'ü deney grubunda, 33'ü ise kontrol grubunda yer almaktadır. Kontrol ve deney grupları belirlenirken fen bilimleri dersi 6. sinıf yılsonu ortalamaları birbirine en yakın sinuflar seçilmiştir. Deney grubunda yer alan öğrencilerin $15^{\prime} \mathrm{i} \mathrm{k1z}, 18^{\prime} \mathrm{i}$ erkek, kontrol grubunda yer alan öğrencilerin ise 16's1 kız, 17'si erkek öğrencilerdir. Toplamda ise 31 kız ve 35 erkek öğrenci araştırmada yer almıştır.

\section{Veri Toplama Araçları}

Araştırmanın verilerinin toplanmasında Öğrenci Bilgi Formu ve Fen Bilimleri Dersi Akademik Başarı Testi kullanılmıştır.

Öğrenci Bilgi Formu: Araştırmada yer alan öğrencilerin cinsiyet, internete sahip olma, bilgisayar ve internet kullanabilme düzeylerinin araştırılması için araştırmacı tarafından hazırlanmıştır. Bu form ile grupların belli ölçütlere göre denkliğinin araştırılması ve öğrencilerin uygulama öncesi bilgisayar ve internet kullanabilme düzeyleri hakkında bilgi toplanması amaçlanmıştır.

Fen Bilimleri Dersi Akademik Başarı Testi: Araştırmada öğrencilerin uygulama öncesi ve uygulama sonrası ders başarılarını ölçebilmek için araştırmacı tarafından 7. sınıf Fen Bilimleri Dersi "Vücudumuzdaki Sistemler" ünitesi için "Fen Bilimleri Dersi Akademik Başarı Testi" hazırlanmıştır. Kapsam geçerliliğini sağlamak için, öncelikle uygulamada yer alacak ünitelere göre belirtke tablosu hazırlanmış ve tüm konuları kapsayacak şekilde 52 adet soru hazırlanmıştır. Bu soruların hazırlanmasında MEB ders kitapları ve sınavlara hazırlık test kitaplarından faydalanılmıştır. Hazırlanan sorular uzman görüşlerine dayanarak yeniden düzenlenmiş ve pilot uygulamaya hazır hale getirilmiştir. Pilot uygulama olarak test, 8. sinıfta okuyan 202 öğrenciye uygulanmıştır. Test maddelerinin, madde güçlük indeksleri ve madde ayırıcllık indeksleri hesaplanmıştır. Buna göre madde güçlük indeksi 0,25 ile 0,75 arasinda olan ve madde ayırıcilık indeksi 0,30'un üzerinde olan 43 madde Fen Bilimleri Dersi Akademik Başarı Testini oluşturmuştur. Bu değerlerin d1şında olan 9 madde testten çıarılmıştır. Oluşturulan 43 maddelik testin pilot 
uygulama sonuçlarına göre testin ortalama madde güçlük indeksi 0,47 ortalama ayırıcllık indeksi ise 0,38 olarak bulunmuştur. Testte bulunan her soru 1 puan değerindedir ve testten en fazla 43 puan, en düşük 0 puan alınabilmektedir. Testin güvenirliğine yönelik yapılan analizde KR-20 güvenirlik katsayısı 0,87 olarak hesaplanmıştır. Buna göre testin güvenilir olduğu söylenebilir.

Deneysel İşlemler: Uygulama yapılacak okul belirlenirken öncelikli özel okullar araştırılmıştır. Bunun için belirlenen birkaç özel okulla görüşmeler yapılmış ancak fen bilimleri ders saatinde uygulama yapma konusunda okulların izni olmamıştır. Ders süresi dışında bilgisayar dersi içerisinde yapılması konusunda bir özel okul ile anlaşılmıştır. Ancak bilgisayar dersinin seçmeli ders olması ve dönem başladığında dersin yeterince öğrenci tarafından seçilmemiş olmasından dolayı bilgisayar dersi olmamış ve dolayısıyla bu okulda araştırma yapılamamıştır. Özel okulların ders saati içinde uygulama konusundaki hassasiyetten dolayı araştırmanın devlet okulunda yapılmasına karar verilmiştir. İlgili kurumlardan izinler alınarak bir devlet ortaokulunda araştırma yapılmıştır.

Ön-test son-test kontrol gruplu yarı deneysel desen olan uygulama 20172018 Eğitim Öğretim yılı 1. döneminde yapılmıştır. Okul yönetiminden alınan 7. sınıf fen bilimleri dersi ünitelendirilmiş yıllık plana göre öğrenme alanı olarak "Canlılar ve Hayat", ünite olarak "Vücudumuzdaki Sistemler" belirlenmiş ve uygulama 7 hafta sürmüştür. Uygulama öncesi kontrol ve deney grubu olarak belirlenen öğrencilere ön-test olarak "Fen Bilimleri Dersi Akademik Başarı Testi" uygulanmıştır.

Fen Bilimleri Dersi Öğretim Programının oluşturulmasında genel olarak öğrencinin, kendi öğrenmesinden sorumlu olduğu, öğrenme sürecine aktif katılımının sağlandığı bilgiyi kendi zihninde yapılandırmaya olanak tanıyan yapılandırmacılık yaklaşımı benimsenmiştir (MEB, 2013). Dolayısıyla hazırlanan ders kitapları ve bu kitaplarda yer alan içerik ve etkinlikler yapılandırmacı yaklaşıma uygun olarak hazırlanmaktadır. Uygulamanın yapıldığ okuldaki fen bilimleri dersi öğretmenlerinin derslerinde kullandıkları yöntem, teknikler ve ders kitapları incelendiğinde yapılandırmacı yaklaşıma uygun olduğu görülmüştür. Bu durum göz önünde bulundurularak kontrol grubunda yapılandırmacı yaklaşımın benimsendiği mevcut programa göre fen bilimleri dersi yapılmıştır. Deney grubunda ise mevcut yapılandırmacı 
öğretim programına ek olarak araştırmacı tarafından tasarlanan çoklu ortam tasarımı destekli etkinlikler uygulanmıştır. Bu etkinlikler fen bilimleri dersi için belirlenen mevcut ders saatleri içerisinde yapılmıştır ve ek bir süre kullanılmamıştır. Haftalık 6 ders saati olan fen bilimleri dersinin 4 saatinde öğretmen mevcut programa göre derslerini yaparken, 2 saatlik süre içerisinde ise araştırmacı tarafından çoklu ortam tasarımı etkinlikleri uygulanmıştır.

Uygulamada her bir konu için etkinlik planları hazırlanmıştır. Bu planlarda öğrencilere neler yapacakları konusunda bilgilendirmeler ve benzer Scratch proje örneklerinin yer aldığı web sayfası linkleri verilmiştir. Öğrencilere her konu ile ilgili görevler verilmiş ve tasarlanacak çoklu ortamın nasıl olacağı konusunda yönlendirmeler yapılmıştır. Öğrenciler 2-3 kişilik gruplar halinde tasarımlarını hazırlamışlardır. Çoklu ortam tasarımında Scratch yazılımı kullanılmıştır. Scratch yazılımını deney grubundaki öğrenciler bir önceki eğitim öğretim yılında ders olarak gördükleri için, uygulama öncesi yazılımın kullanımıyla ilgili genel bilgilendirme ve hatırlatmalar yapılmıştır. Araştırmacı tarafından Scratch web sayfasından öğretmen hesabı açılıp bir sınıf oluşturulmuş ve deney grubunda yer alan öğrenciler bu sınıfa eklenmiştir.

Her bir öğrenci için kullanıcı adı ve şifresi belirlenerek öğrencilere iletilmiştir. Öğrenciler bu hesaplara giriş yaparak tasarımlarını oluşturmuş ve s1nıf içerisinde yapılan tüm tasarımları görerek arkadaşlarının yaptıkları tasarımlar ile ilgili değerlendirmeler yapabilmiştir.

Uygulama sonrası, kontrol ve deney grubu olarak belirlenen öğrencilere son-test olarak tekrar "Fen Bilimleri Dersi Akademik Başarı Testi" uygulanmıştır.

\section{Verilerin Analizi}

Uygulama sonrası testten elde edilen nicel veriler SPSS programına girilerek düzenlenmiştir. Bu veriler ile betimsel analiz yapılmıştır. Grupların aritmetik ortalaması, standart sapması, çarpıklık ve basıklık katsayıları, minimum ve maksimum değerleri hesaplanmıştır. Deney gruplarına ve kontrol grubuna ait ön-test akademik başarı puanlarından elde edilen verilere bağımsız örneklem t-testi yapılmış ve gruplar arasında istatistiksel olarak anlamlı bir farklılık olup olmadığı incelenmiştir. Ön-testler arasında anlamlı bir farklılık olmamasına rağmen ortalamalardaki farklılıkların etkisinin ortadan kaldırılması 
amaciyla son-testler üzerinde tek yönlü kovaryans analizi (ANCOVA) yapılmış ve ön-testler ortak değişken olarak kullanılmıştır. ANCOVA analizi gruplar arasında önceden oluşan farklılığı düzeltmek amaciyla kullanıldığı gibi ayrıca, hata varyansını düşürerek istatistiksel gücü ve tahminin doğruluğunu artırdığından ortak değişkene ilişkin deney gruplarının anlamlı bir şekilde farklılaşmaması durumunda dahi kullanılabilen güçlü bir tekniktir (Büyüköztürk, 1998). Bu tekniğin kullanılabilmesi için araştırma sürecinde öncelikle ANCOVA'nın varsayımlarının karşılanıp karşılanmadığını kontrol edilmesi gereklidir. ANCOVA analizinin varsayımları şu şekildedir (Büyüköztürk, 2011; Çokluk, Şekercioğlu ve Büyüköztürk, 2010; Mertler ve Vannatta, 2002):

- Gruplarda gerçekleştirilen gözlemler rastgele ve birbirinden bağımsızdır.

- Bağımlı değişkene ait puanların evrendeki dağılımı normaldir.

- Bağımlı değişkene ait puanların varyansları homojendir.

- Bağımlı değişken ile ortak değişken(ler) arasında doğrusal bir ilişki vardır.

- Gruplar için regresyon doğrularının eğimleri homojendir.

\section{Bulgular}

Bu bölümde çoklu ortam tasarımı destekli yapılandırmacı öğretim etkinliklerinin uygulandığı deney grubu ile mevcut eğitim programının uygulandığı kontrol grubunun akademik başarılarını belirlemeye yönelik yapılan "Fen Bilimleri Dersi Akademik Başarı Testi” sonuçlarına ilişkin bulgular yer almaktadir.

\section{Fen Bilimleri Dersi Akademik Başarı Ön-test Puanlarna İlişkin Bulgular}

Grupların akademik başarı ön-test sonuçlarının analizi için bağımsız örneklem t-testi uygulanmıştır. Bunun öncesinde grupların normal dağılım gösterip göstermediğini incelemek amacıyla basıklık ve çarpıklık katsayılarına bakılmıştır. Grupların akademik başarı ön-test puanlarına ilişkin betimsel istatistik sonuçları Tablo-1' de verilmektedir.

Tablo 1. Akademik Başarı Ön-test Puanlarının Betimsel İstatistik Sonuçlan

\begin{tabular}{llllllll}
\hline Grup & $\mathrm{N}$ & $\bar{X}$ & SS & Min & Maks & BK & ÇK \\
\hline Deney & 33 & 22,88 & 4,94 & 11 & 33 & 0,146 & $-0,273$ \\
\hline Kontrol & 33 & 25,36 & 5,63 & 12 & 35 & $-0,236$ & $-0,192$ \\
\hline
\end{tabular}


Basıklık (BK) ve çarpıklık (ÇK) katsayıları incelendiğinde grupların normal dağılım gösterdikleri görülmektedir. Deney ve kontrol gruplarının akademik başarı ön test sonuçlarının karşılaştırılması için yapılan bağımsız örneklem t-testi sonuçları Tablo-2' de verilmektedir.

Tablo 2. Akademik Başarı Ön-test Puanları t-testi Sonuçlan

\begin{tabular}{llllll}
\hline Grup & $\mathrm{N}$ & $\bar{X}$ & SS & $\mathrm{t}$ & $\mathrm{p}$ \\
\cline { 1 - 3 } Deney & 33 & 22,88 & 4,94 & \multirow{2}{*}{$-1,906$} & \multirow{2}{*}{0,061} \\
\hline Kontrol & 33 & 25,36 & 5,63 & & \\
\hline
\end{tabular}

Sonuçlar incelendiğinde kontrol grubu akademik başarı ön-test ortalamaSinın $(\bar{X}=25,36$; SS=5,63), deney grubu akademik başarı ön-test ortalamasından $(\bar{X}=22,88 ; S S=4,94)$ yüksek olduğu görülmektedir. Ancak bu fark istatistiksel olarak anlamlı bulunmamıştır $(t=1,906, p>0,05)$. Yani grupların akademik başarı ön test sonuçları arasında anlamlı bir farklılık yoktur. Buna göre uygulama öncesi grupların akademik başarı açısından denk olduğu söylenebilir.

\section{Fen Bilimleri Dersi Akademik Başarı Son-test Puanlarına İlişkin Bulgular}

Grupların akademik başarı ön-test puanları kontrol altına alındığında sontest puanlarının analizi için tek yönlü ANCOVA yapılmıştır. Bunun öncesinde ANCOVA yapılabilmesi için gerekli varsayımların kontrolü sağlanmıştir.

Grupların akademik başarı ön-test ve son-test değerlerine ilişkin betimsel istatistikler Tablo-3'te verilmektedir.

Tablo 3. Gruplarn Akademik Başarı Ön-test ve Son-test Puanlarnın Betimsel İstatistik Sonuçları

\begin{tabular}{lllllllll}
\hline Grup & Test & \multirow{2}{*}{ N } & $\bar{X}$ & SS & Min & Maks & BK & \multicolumn{2}{c}{ ÇK } \\
\hline \multirow{2}{*}{ Deney } & Ön-test & \multirow{2}{*}{33} & 22,88 & 4,94 & 11 & 33 & 0,146 & $-0,273$ \\
& Son-test & & 37,52 & 3,31 & 32 & 43 & $-0,991$ & $-0,150$ \\
\hline \multirow{2}{*}{ Kontrol } & Ön-test & \multirow{2}{*}{33} & 25,36 & 5,63 & 12 & 35 & $-0,236$ & $-0,192$ \\
& Son-test & \multirow{2}{*}{36,27} & 3,79 & 26 & 43 & 0,887 & $-0,571$ \\
\hline
\end{tabular}

Deney ve kontrol gruplarının akademik başarı testi ön-test, son-test basıklık ve çarpıklık katsayıları incelendiğinde sonuçların normal dağılım varsayımını karşıladığı görülmektedir. Ayrıca normallik için yapılan Shapiro-Wilk testi sonuçlarına göre kontrol grubu istatistik değeri $0,959(p=0,243>0,05)$ ve 
deney grubu istatistik değeri $0,953(\mathrm{p}=0,158>0,05)$ bulunduğundan grupların akademik başarı testi sonuçlarının normal dağılım gösterdiği söylenebilir.

Diğer varsayım olan grup varyanslarının homojen olup olmadığını belirlemek için Levene testi sonuçlarına bakılmış ve istatistiksel olarak anlamlı bir farklılık olmadığ1 görülmüştür. $\left(F_{1,64}=0,006 ; \mathrm{p}=0,938>0,05\right)$. Bu sonuca göre grupların akademik başarı testi son-test puanlarına ilişkin varyansları homojendir.

Bağımlı değişken ile ortak değişken arasında doğrusal bir ilişki olup olmadığının test edilmesi amaciyla yapılan Pearson korelasyon analizi sonuçları Tablo-4'te verilmektedir.

Tablo 4. Akademik Başarı Ortak Değişken ve Bağımlı Değişken Arasındaki İlişki

\begin{tabular}{llll}
\hline Grup & Test & $\mathrm{r}$ & $\mathrm{p}$ \\
\hline Deney & Ön-test/Son-test & 0,738 & $<0,001$ \\
\hline Kontrol & Ön-test / Son-test & 0,743 & $<0,001$ \\
\hline
\end{tabular}

Tablo-4'e göre grupların akademik başarı ön-test ve son-test sonuçları arasında anlamlı bir ilişki olduğu görülmektedir. Grupların ön-test ve son-test akademik başarı puanları arasındaki ilişkilerin doğrusallığı Şekil-1'de verilmektedir. 


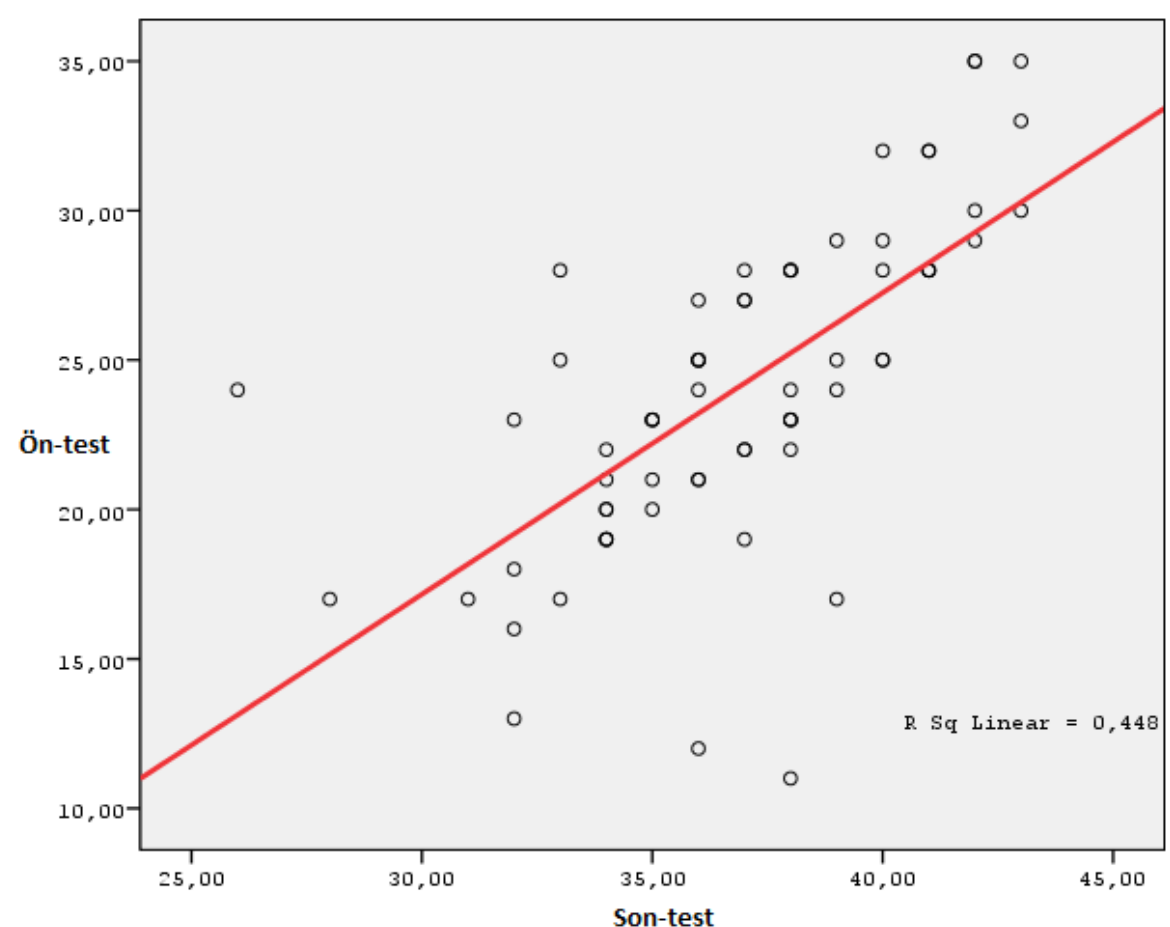

Şekil 1. Akademik Başarı Ön-test Son-test Puanları Arasındaki İlişkiyi Gösteren Saçılma Diyagrame

Regresyon doğrularının eğimlerinin homojenliği ile ilgili varsayımı test etmek amacıyla yapılan ANCOVA analizi sonuçları Tablo-5'te verilmektedir.

Tablo 5. Akademik Başam Regresyon Doğrularmın Ĕ̆imlerinin Homojenliği

\begin{tabular}{llllll}
\hline Varyansın Kaynağı & Kareler Toplamı & Sd & $\begin{array}{l}\text { Kareler Ortala- } \\
\text { mas1 }\end{array}$ & $\mathrm{F}$ & $\mathrm{p}$ \\
\hline Grup & 5,029 & 1 & 5,029 & 0,855 & 0,359 \\
\hline Ön-test & 435,917 & 1 & 435,917 & 74,095 & $<0,001$ \\
\hline Grup X Ön-test & 0,015 & 1 & 0,015 & 0,003 & 0,959 \\
\hline Hata & 364,760 & 62 & 5,883 & & \\
\cline { 1 - 2 } Toplam & 90671,000 & 66 & \multicolumn{3}{l}{} \\
\cline { 1 - 2 }
\end{tabular}

Tablo-5 incelendiğinde, öğrencilerin akademik başarı son-test puanları üzerinde GrupXÖn-test ortak etkisinin anlamsız olduğu görülmektedir $\left(F_{1-62}=0.003, \mathrm{p}=0,959>0.05\right)$. Buna göre regresyon doğrularının eğimlerinin homojen olduğu söylenebilir. 
Yapılan analizlere göre ANCOVA analizi için gerekli tüm varsayımlar sağlanmıştır. Grupların akademik başarı testi düzeltilmiş son-test puan ortalamaları arasındaki farkın anlamlı olup olmadığına ilişkin yapılan ANCOVA analizi sonuçları Tablo-6' da verilmektedir.

Tablo 6. Akademik Başarı Testine İlişkin ANCOVA Sonuçları

\begin{tabular}{lllllll}
\hline Varyansın Kaynağı & $\begin{array}{l}\text { Kareler Top- } \\
\text { lamı }\end{array}$ & Sd & $\begin{array}{l}\text { Kareler Ortala- } \\
\text { masi }\end{array}$ & F & p & @2 \\
\hline Ön-test & 444,013 & 1 & 444,013 & 76,685 & $<0,001$ & 0,55 \\
\hline Grup & 95,894 & 1 & 95,894 & 16,562 & $<0,001$ & 0,21 \\
\hline Hata & 364,775 & 63 & 5,790 & & & \\
\hline Toplam & 90671,000 & 66 & & & & \\
\hline
\end{tabular}

Tablo-6'ya göre deney ve kontrol gruplarının ön-test puanlarına göre düzeltilmiş son-test akademik başarı puan ortalamaları arasında istatistiksel olarak anlamlı bir farklılık olduğu görülmektedir $\left(F_{1-63}=16.562 ; \mathrm{p}<0.01\right)$. Bu sonuç, uygulanan deneysel işlemin deney grubu öğrencilerinin Fen Bilimleri dersi akademik başarılarını anlamlı bir şekilde artırdığını göstermektedir. Gruplar üzerinde uygulanan deneysel işlemin akademik başarı üzerindeki etki büyüklüğü (Kısmi @2 ) 0,21 olarak hesaplanmıştır. Bu sonuç bağımlı değişkendeki değişimin \%21'inin uygulanan yöntemden kaynaklandığını göstermektedir.

Deneysel işlem sonrasında grupların akademik başarı ön-test puanlarına göre düzeltilmiş son-test ortalama puanları Tablo-7' de verilmiştir.

Tablo 7. Akademik Başan Testine İlişkin Ortalama Puanlar

\begin{tabular}{lccccccc}
\hline \multirow{2}{*}{ Grup } & \multirow{2}{*}{$\mathrm{N}$} & Ön-test & \multicolumn{3}{c}{ Son-test } & \multicolumn{3}{c}{ Düzeltilmiş Son-test } \\
\cline { 3 - 7 } & & $\bar{X}$ & SS & $\bar{X}$ & SS & $\bar{X}$ & SH \\
\hline Deney & 33 & 22,88 & 4,94 & 37,52 & 3,31 & 38,13 & 0,43 \\
\hline Kontrol & 33 & 25,36 & 5,63 & 36,27 & 3,79 & 35,66 & 0,43 \\
\hline
\end{tabular}

Tablo-7 incelendiğinde öğrencilerin deneysel işlem sonrasında akademik başarı testinden aldıkları puanların ortalamalarının deney grubundaki öğrenciler için 37,52, kontrol grubundaki öğrenciler için 36,27 olduğu görülmektedir. Akademik başarı ön-test puanlarına göre düzeltilmiş son-test puanlarının ortalaması deney grubunda 38,13, kontrol grubunda 35,66 olarak hesaplanmıştır. Buna göre deney grubu düzeltilmiş son-test ortalama puanı, kontrol grubu düzeltilmiş son-test ortalama puanından 2,47 puan yüksek olduğu görülmektedir. 
Sonuç olarak, deneysel uygulama öncesi gruplar arasında ön-test akademik başarı puanlarına göre anlamlı bir fark çıkmazken, deneysel uygulamanın sonunda elde edilen son-test puanlarına göre deney grubu lehine anlamlı bir farklılık ortaya çıkmıştır. Çoklu ortam tasarımı destekli yapılandırmacı öğretim etkinlikleri gerçekleştiren deney grubu, sadece ders programını uygulayan kontrol grubuna göre daha başarılı olmuştur.

\section{Tartışma ve Sonuç}

Çalışmada çoklu ortam tasarımı destekli yapılandırmacı öğretim etkinliklerinin öğrencilerin akademik başarısına etkisini incelemek amacıyla deney grubu ve kontrol grubunda yer alan öğrencilerin Fen Bilimleri dersi akademik başarıları karşılaştırılmıştır. Deneysel uygulama sonucunda deney ve kontrol gruplarının akademik başarılarında artış gözlenmiş ancak deney grubundaki artış kontrol grubuna göre anlamlı bir şekilde daha fazla olmuştur. Uygulama öncesi gruplara uygulanan akademik başarı ön-test sonuçlarına göre gruplar arasında farklılık bulunmazken uygulama sonrasında deney grubu lehine anlamlı bir farklılık ortaya çıkmıştır. Buna göre çoklu ortam tasarımı destekli yapılandırmacı öğretim etkinliklerinin öğrencilerin akademik başarılarını artırdığı sonucuna ulaşılmıştır. İlgili literatür incelendiğinde çoklu ortam tasarımı konusunda yapılan çalışmalarda benzer sonuçların yer aldığ1 görülmektedir (Carver, Lehrer, Connell ve Erickson, 1992; Lehrer, Erickson ve Connell, 1994; Hay, Guzdial, Jackson, Boyle ve Soloway, 1994; Erickson, 1997; Liu ve Pedersen, 1998).

Carver, Lehrer, Connell ve Erickson (1992), yaptıkları çalışmalarında çoklu ortam tasarımı içeren ders öğrenmeleri etkinliklerinde öğrencilerin tasarım becerilerini geliştirmenin yanında ders konularıyla ilgili de öğrenme gerçekleştiğini belirtmişlerdir. Lehrer, Erickson ve Connell (1994) de çalışmalarında planlanmamasına rağmen çoklu ortam tasarımı yaptırdıkları öğrencilerde "bilgiyi bulma, yorumlama, bilgi aktarma ve bilgisayarlanı bilişsel araçlar olarak kullanma" gibi diğer içeriklere transfer edebilecekleri çeşitli yararlı beceriler geliştirdiklerini ve önemli bir nokta olarak da bilginin "öğretmenlerden veya metinlerden değil öğrencilerin yapılandırmacı çabalarının bir sonucu" olduğunu gözlemlediklerini belirtmişlerdir.

Buna benzer yapılan araştırmalar, öğrencilerin kendi çabalarıyla motive olarak kendi bilgilerini yapılandırmalarının ve bu bilgilere değer vermelerinin akademik başarılarını artırdığını göstermektedir. 
Genel olarak öğrenciler derslerde kendi çabalarıyla ortaya koydukları ve değer gören etkinlikler gerçekleştirdiklerinde yüksek motivasyon ve tutum göstererek anlamlı öğrenmeler gerçekleştirebilmektedir. Bu da onların daha fazla çaba ve özveri gösterip sorumluluk alabileceklerinin bir göstergesi olmaktadır. Bu şekilde gerçekleştirilen dersler öğrencileri pasif dinleyici konumdan çıkararak etkin hale getirmektedir. Görsel ve uygulamalı olarak yapılan etkinlikler konuların daha akılda kalıcı olmasını sağlamış ve akademik başarının artmasında etkili olmuştur.

Sonuç olarak mevcut uygulamaları kullanmak yerine bireyin kendi tasarladığ1 ve ürettiği her türlü ürünün çok daha değerli olduğu günümüzde, öğrenciler tarafindan çoklu ortam oluşturularak gerçekleştirilen etkinliklerin mevcut yapılandırmacı öğretim sürecinde kullanıldığı bu araştırmanın, gelişen teknolojinin eğitim-öğretim sürecine dahil edilmesinde etkili bir yöntem olarak kullanılabileceği söylenebilir.

Araştırma sonuçlarına göre şu öneriler getirilebilir:

Çoklu ortam tasarımı destekli yapılandırmacı öğretim etkinliklerinin öğrencilerin fen bilimleri dersi kapsamında akademik başarısını artırdığı sonuçları ortaya konmuştur. Bu etkinlikler diğer derslerde ve diğer sınıf seviyelerinde gerçekleştirilebilir.

Çoklu ortam tasarım aracı için araştırmacı tarafindan "Scratch" uygun görülmüştür. Yapılacak etkinliklerde diğer çoklu ortam tasarım araçları da kullanılıp hangi aracın daha etkili olduğu araştırılabilir.

Etkinliklerde öğrencilerin zaman zaman kodlama yaparken zorlandıkları noktalar olduğu gözlenmiştir. Scratch ve benzeri araçların çok ortam tasarım aracı olarak kullanılacağı etkinliklerde öğrencilerin zorlanmamaları ve daha etkili ürünler ortaya koymalarını sağlamak için öğrencilere ders dışı zamanlarda eğitim verilebilir veya Bilgisayar derslerinde buna yönelik çalışmalar yapılabilir.

Bu çalışma kapsamında etkinliklerin akademik başarı değişkeni üzerine etkisi araştırılmıştır. Çoklu ortam tasarımı destekli yapılandırmacı öğretim etkinliklerinin farklı değişkenler üzerinde etkisi araştırılabilir.

Bu tür yazılımlar genelde çevrimiçi platformlar olduğundan öğrenciler ile ilgili bilgilerin sunucu servisler tarafından toplanıp incelenmesi olasıdır. Bu tür durumların ülke aleyhine kullanılmasını önlemek üzere Scratch benzeri milli yazılımlar geliştirilebilir. 
EXTENDED ABSTRACT

\title{
The Impact Of Academic Achievement Of Constructivist Teaching Activities With Multimedia Design On Students
}

\author{
Cemal Akyol \\ Selçuk University
}

In the information age, skills such as accessing, using and producing information are important factors that shape the future of societies. Contemporary and innovative learning approaches are needed for individuals to acquire these skills. In the period when traditional approaches were insufficient, the constructivism approach, which is an approach based on the foundation of knowledge and how learners construct knowledge, came to the fore.

The development of technology has an impact on all life. It enables many innovations, especially in the field of education. Technological investments in education in Turkey has increased in the recent period. With the FATIH project, it is aimed to equip all classrooms with technological facilities such as smart boards, internet connections, projectors, and also to distribute free tablet computers to all students and teachers, and to make the most of technology in education. Technology should be used in designing the necessary environments for learners to have rich learning experiences in accordance with the understanding of constructivism (Jonassen, 1999). Through computers, which make the most of technological opportunities in the field of education, students can access various multimedia tools such as stories, interactive games, animations, simulations and use them for educational purposes. However, they can only use these limited software made by others, but they cannot make it themselves. Developing software on the computer, creating games or animations is seen as a difficult and specialized job (Jenkins, 2002). In order to eliminate all these negative conditions, a software called Scratch was prepared by MIT and made available to everyone free of charge. Scratch software is a visual programming tool that allows the creation of rich twodimensional multimedia tools. Environments such as games, animated stories, greeting cards, music videos, science projects, trainings, simulations and 
art projects can be created easily with this software. In Scratch software, the coding system is designed as colored blocks that complement each other. This design has made coding both visual and easy. Scratch software is especially designed for children aged 8-16, but is used by people of all ages. The software has been downloaded by more than two million people since 2007, when it was available in 50 different languages, including Turkish. As a result, Scratch software has become an environment that is easy to learn, complex projects can be done easily and project diversity is supported (Maloney et all., 2010; Genç and Karakuş, 2011).

Technological developments affect education and enable the existing teaching activities to be enriched. Considering the current education programs where the constructivism approach is at the center, enriching the teaching activities will increase the motivation, interest and attention of the students and the learning will be more effective, enjoyable and permanent. In this context, the use of multimedia created by technology makes a difference in education. However, the multimedia used in education are usually designed and created by teachers or experts. In this case, the student being passive and the teacher being active is contrary to the principles of the constructivist approach. In this context, the general purpose of this study, in which students create their own multimedia materials and actively participate in the education process in accordance with the constructivist approach, was to investigate the effect of constructivist teaching activities supported by multimedia design on secondary school students. For this purpose, the effects of multimedia aided constructivist teaching activities on students' academic achievement were investigated within the scope of the 7th grade Science course.

Accordingly, the effects of multimedia aided constructivist teaching activities implemented in 7th grade Science Course were examined in terms of students' academic achievement, attitudes to the course, and motivation for learning science.

The study adopted a mixed research design, which involves both quantitative and qualitative methods. A pre-test post-test control group design, one of the quantitative research methods, was used in order to determine the effects of the experimental application on learning products. The study group consisted of 66 students attending the 7th grade of a secondary school in Konya city centre. The research was conducted in 7th grade Science Course. In the study, there were randomly selected two groups, one experimental and 
one control group. The course was given according to the current Science curriculum in the control group. On the other hand, multimedia aided constructivist teaching activities, which were designed by the researcher, were implemented in the experimental group in addition to the current Science curriculum. Descriptive statistics, independent samples t-test and one-way covariance analysis (ANCOVA) were used to analyze the quantitative data of the study. Qualitative data was analyzed descriptively in a case study design.

The findings of the research concluded that multimedia aided constructivist teaching activities had a positive effect on students' academic achievement, attitudes to the science course, and motivation for learning science.

\section{Kaynakça / References}

Arslan, A. (2008). Yapılandırmacı öğrenme yaklaşımına göre hazırlanan Türkçe Dersi öğretim programını uygulanmasına ilişkin öğretmen görüşlerinin değerlendirilmesi. Yayınlanmamış Doktora Tezi. Atatürk Üniversitesi Sosyal Bilimler Enstitüsü, Erzurum.

Brooks J. G. ve Brooks, M. G. (1999). The courage to be constructivist. Educational Leadership, 18-24.

Büyüköztürk, Ş. (2011). Sosyal bilimler için veri analizi el kitabı (14. Baskı). Ankara: Pegem Akademi.

Carver, S. M., Lehrer, R., Connell, T., ve Erickson, J. (1992). Learning by Hypermedia Design: Issues of assessment and implementation. Educational Psychologist, 27(3), 385-404.

Çokluk, Ö., Şekercioğlu, G., ve Büyüköztürk, Ş. (2010). Sosyal bilimler için çok değiş̧enli istatistik: SPSS ve LISREL uygulamalarn. Ankara: Pegem Akademi.

Demirel, Ö. (2012). Eğitimde program geliştirme. Ankara: Pegem Akademi.

Erickson, J. (1997). Building a community of designers: Restructuring learning through student hypermedia design. Journal of Research in Rural Education, 13(1), 5-27.

Eskici, M. (2013). Ilköğretim öğretmenlerinin yaplandirmac yaklaşıma ilişkin öz yeterlik algları ile tutumları. Yayınlanmamış Doktora Tezi. Abant İzzet Baysal Üniversitesi Eğitim Bilimleri Enstitüsü, Bolu.

Hay, K. E., Guzdial, M., Jackson, S., Boyle, R. A., ve Soloway, E. (1994). Students as multimedia composers. Computers and Education, 23(4), 301-317.

Hesapçığlu, M. (2011). Öğretim ilke ve yöntemleri eğitim programları ve öğretim (7. Bask)). Ankara: Nobel Yayın Dağıtım. 
Jenkins, T. (2002). On the difficulty of learning to program. 3rd Annual Conference Of The LTSN Centre For Information And Computer Sciences, Loughborough University, Leicestershire, UK.

Jonassen, D. H. (1994). Thinking technology: Toward a constructivist design model. Educational Technology, 34(4), 34-37.

Jonassen, D. H. (1999). Designing constructivist learning environments. (Ed. C. M. Reigeluth), Instructional Theories And Models içinde (s.215-239), Mahwah, NJ: Lawrence Erlbaum Associates.

Kurtdede Fidan, N. (2010). Sinı öğretmenlerinin yapılandırmacı yaklaşımın gerektirdiği niteliklere sahip olma düzeylerinin değerlendirilmesi: Afyonkarahisar İli örneği. Yayınlanmamış Doktora Tezi, Gazi Üniversitesi Eğitim Bilimleri Enstitüsü, Ankara.

Lehrer, R., Erickson, J. ve Connell, T. (1994). Learning by designing hypermedia documents. Computers in the Schools, 10(1/2), 227-254.

Liu, M., ve Pedersen, S. (1998). The effect of being hypermedia designers on elementary school students' motivation and learning of design knowledge. Journal of Interactive Learning Research, 9(2), 155-182.

Maloney, J., Peppler, K., Kafai, Y., Resnick, M. ve Rusk, N. (2008). Programming by choice: Urban youth learning programming with scratch. Proceedings of the 39 th SIGCSE technical symposium on Computer science education. 367-371.

Maloney, J., Resnick, M., Rusk, N., Silverman, B. ve Eastmond, E. (2010). The scratch programming language and environment. ACM Transactions on Computing Education (TOCE), 10(4).

Mertler, C. A., ve Vannatta, R. A. (2002). Advanced and multivariate statistical methods: Practical application and interpretation (2nd Ed.). Los Angeles: Pyrczak Publishing.

Peppler, K. ve Kafai, Y. (2007). From supergoo to scratch: exploring creative digital media production in informal learning. Learning, Media and Technology. Special Issue: Media Education Goes Digital. 32(2).

Perkins, D. N. (1999). Technology meets constructivism: Do they make a marriage? Ed. T. M. Duffy ve D. H. Jonassen, Constructivism And The Technology Of Instruction: A Conversation. New Jersey: Lawrence Erlbaum Associates Publishers.

Resnick, M., Maloney, J., Monroy-Hernandez, A., Rusk, N., Eastmond, E., Brennan, K., Millner, A., Rosenbaum, E., Silver, J., Silverman, B. ve Kafai, Y. (2009). Scratch: programming for all. Communications of the ACM, 52(11), 60-67 ACM New York, NY, USA.

Senemoğlu, N. (2009). Gelişim, öğrenme ve öğretim: Kuramdan uygulamaya (14. Baskl). Ankara: Pegem Akademi. 


\section{Kaynakça Bilgisi / Citation Information}

Akyol, C. ve Çiftçi, S. (2020). Çoklu ortam tasarımı destekli yapılandırmacı öğretim etkinliklerinin öğrencilerin akademik başarılarına etkisi. OPUS-Uluslararası Toplum Araştırmaları Dergisi, 16(31), xx-xx. DOI: 10.26466/opus.774891 